ORIGINAL ARTICLE

\title{
Histology of the fascial-periosteal interface in lower limb chronic deep posterior compartment syndrome
}

\author{
T D A Barbour, C A Briggs, S N Bell, C J Bradshaw, D J Venter, P D Brukner
}

Br J Sports Med 2004;38:709-717. doi: 10.1136/bjsm.2003.007039

See end of article for authors' affiliations

Correspondence to: Dr Barbour, Centre for Sports Medicine Research and Education, University of Melbourne, Melbourne, Victoria 3010, Australia; t.barbour@pgrad.unimelb. edu.au

Accepted 6 October 2003
Objective: To describe the histological features of the fascial-periosteal interface at the medial tibial border of patients surgically treated for chronic deep posterior compartment syndrome and to make statistical comparisons with control tissue.

Methods: Nineteen subjects and 11 controls were recruited. Subject tissue was obtained at operation, and control tissue from autopsy cases. Tissue samples underwent histological preparation and then examination by an independent pathologist. Samples were analysed with regard to six histological variables: fibroblastic activity, chronic inflammatory cells, vascularity, collagen regularity, mononuclear cells, and ground substance. Collagen regularity was measured with respect to collagen density, fibre arrangement, orientation, and spacing. The observed changes were graded from 1 to 4 in terms of abnormality. Mann-Whitney U test, Spearman correlation coefficients, and intraobserver reliability scores were used.

Results: With regard to collagen arrangement, control tissue showed greater degrees of irregularity than subject tissue $(p=0.01$ ). Subjects with a symptom duration of greater than 12 months (as opposed to less than 12 months) showed greater degrees of collagen irregularity ( $p=0.043$ ). Vascular changes approached significance $(p=0.077$ ). With regard to the amount of fibrocyte activity, chronic inflammatory cell activity, mononuclear cells, or ground substance, there were no significant differences between controls and subjects. Good correlation was seen in scores measuring chronic inflammatory cell activity and mononuclear cells $(r=0.649)$, and moderate correlation was seen between fibrocyte activity and vascular changes $(r=0.574)$. Intraobserver reliability scores were good for chronic inflammatory cell activity and moderate for vascular changes, but were poor for collagen and fibrocyte variables. Individual cases showed varying degrees of fibrocyte activity, chronic inflammatory cellular infiltration, vascular abnormalities, and collagen fibre disruption.

Conclusions: Statistical analysis showed no histological differences at the fascial-periosteal interface in cases of chronic deep posterior compartment syndrome, except for collagen, which showed less irregularity in subject samples. The latter may indicate a remodelling process, and this is supported by greater collagen irregularity in subjects with longer duration of symptoms.
E xercise associated chronic lower leg pain is common among both recreational and elite athletes. ${ }^{1-6}$ Important differential diagnoses to consider include stress fracture, medial tibial periostalgia, popliteal artery entrapment, and exertional compartment syndromes. ${ }^{6-9}$ Chronic exertional compartment syndrome (CECS) has established itself as an important contributor. In patients with exercise induced leg pain, the diagnosis of CECS was reported to be present in $33 \%^{10}$ and $26 \%{ }^{11}$ of cases. Of patients presenting to an Australian sports medicine centre, 3.5\% were reported to have a compartment syndrome. ${ }^{12}$ With the high prevalence of athletes participating in running and team sports, 95\% of CECS cases affect the lower limb, ${ }^{13}$ with the anterior and deep posterior compartments most commonly involved. ${ }^{14}$ There has been variability in the terminology used to describe CECS and other causes of exercise induced lower leg pain such as medial tibial syndrome, ${ }^{15}$ medial tibial periostitis, ${ }^{16}$ and medial tibial stress syndrome, ${ }^{16}{ }^{17}$ the pathology of which may all merge with CECS. For the purpose of this paper, the clinical entity characterised by exercise induced, inflammatory medial tibial pain with palpatory tenderness of the posteromedial tibial border and often accompanied by patchy linear bony uptake on bone scintigraphy will be referred to as medial tibial stress syndrome (MTSS).

In CECS, pathological increases in muscle compartment pressures produce pain, impairment of neuromuscular function, and reduced performance. Owing to a lack of histological research into this condition, conflicting findings on its inflammatory, fibrocytic, or vascular aetiology, and its clinical similarities to MTSS, the pathophysiology of CECS remains unclear. Given that the pain of CECS is of a crescendo nature, often described as bursting, and largely resolves with cessation of activity, it is understandable that past studies have concentrated on changes in vascular flow. Qvarfordt et al ${ }^{18}$ showed a more pronounced increase in lactate in anterior compartment muscle biopsy specimens immediately after exercise, supporting the opinion that the pain is ischaemic in origin. Other theories supporting vascular flow changes include the presence of pathological increases in muscle relaxation pressure, ${ }^{19}{ }^{20}$ reductions in arteriovenous pressure gradients, ${ }^{21}{ }^{22}$ and the suggestion that reduction in muscle oxygen saturation is more severe and recovery delayed in some patients with chronic anterior compartment syndrome. ${ }^{23}{ }^{24}$ Other studies, however, have not supported the role of ischaemia in the genesis of CECS. ${ }^{95-27}$ Vascular flow imaging techniques using radiopharmaceutical isotopes such as technetium-99 m methoxyisobutyl isonitrile $(\mathrm{MIBI})^{28}$ or thallium-201 single photon emission tomography ${ }^{27}$ have either been inconclusive $e^{28}$ or indicated that there is no compartment perfusion deficit and a non-ischaemic basis for the pain associated with CECS. ${ }^{27}$ An important (but

Abbreviations: CECS, chronic exertional compartment syndrome; MTSS, medial tibial stress syndrome 
nonetheless speculative) concept of its pathogenesis as a cause of medial shin pain is that repetitive mechanical loading on the fascia and its periosteal attachment produce histological changes such as inflammation ${ }^{216}$ and/or fibrosis, ${ }^{26}$ which render the fascia less compliant. ${ }^{26}{ }^{29}{ }^{30}$ With the subsequent increase in muscle volume during exercise, the fascial layer is unable to expand, and pressure within the compartment rises, leading to a compartment syndrome. Continued mechanical loading of these abnormal structures may then worsen these histological changes and result in irreversibly decreased fascial compliance. ${ }^{2}{ }^{30}$ The cascade of physiological events, be they inflammatory, fibrocytic, or vascular may explain the variability of pathological presentations that are often evident or the observed coexistence of CECS with MTSS. ${ }^{17}{ }^{31-33}$

Somewhat surprisingly there have been no studies of the histopathology of the fascial-periosteal interface in patients with CECS of the deep posterior compartment. Repetitive microtrauma at this interface may be responsible for these changes. Therefore we undertook a case-control study of the histological findings in a group of subjects with CECS of the deep posterior compartment, proven by prior compartment pressure studies.

\section{MATERIALS AND METHODS}

Nineteen patients with exercise induced medial shin pain clinically diagnosed as deep posterior compartment syndrome were recruited for the study and had surgery between May 1998 and February 1999 (table 1). There were 10 male and 9 female patients (age range 17-32 years mean 20.4). Symptom duration was 4-60 months (mean 20 months).

\section{Inclusion criteria}

Subjects were recruited after failed conservative treatment consisting of combinations of rest, physiotherapy, massage, and orthotic correction for biomechanical abnormalities. Supportive diagnostic investigations included compartment pressure studies of the deep posterior compartment. These were performed by one of three practitioners experienced in this technique and consisted of a dynamic measurement of the compartment pressure (Intracompartmental Pressure Monitoring System; Stryker, Kalamazoo, Michigan, USA) with correlation of clinical symptoms. A test was regarded as positive if it met the criteria of Pedowitz et al. ${ }^{8}$

\section{Exclusion criteria}

Subjects presenting with exercise induced posteromedial shin pain but with negative compartment pressure studies were excluded from the study. One potential subject was excluded on the basis of the presence of periosteal new bone formation seen on computerised tomography and two others on the basis of questionable compartment pressure results obtained on single stab readings performed in regional centres. One further subject was excluded after it was discovered the consenting procedure had not been stringently adhered to.

\section{Other investigations}

Bone scintigraphy had been performed on 13 of the subjects. Of those, four were reported as normal and nine had changes described as being consistent with shin splints, stress reaction, or periostitis in a patchy or linear distribution. Having bone scintigraphy was not regarded as necessary for inclusion in the study, and having a scan showing the

Table 1 Details of subjects and controls

\begin{tabular}{|c|c|c|c|c|c|c|c|c|c|c|}
\hline & \multirow[b]{2}{*}{ Age } & \multirow[b]{2}{*}{ Side } & \multirow{2}{*}{$\begin{array}{l}\text { Symptom } \\
\text { duration } \\
\text { (months) }\end{array}$} & \multicolumn{6}{|c|}{ Histological scores } & \multirow[b]{2}{*}{ Description } \\
\hline & & & & Fibro & $\mathrm{CIC}$ & Vasc & Coll & Mono & GS & \\
\hline \multicolumn{11}{|c|}{ Subjects } \\
\hline 1 & 22 & $\mathrm{R}$ & 24 & 2 & 1 & 3 & 2 & 1 & 2 & Moderate arterioles \\
\hline 2 & 20 & L & 12 & 1 & 3 & 2 & 1 & 1 & 1 & Lymphocytes and capillaries \\
\hline 3 & 22 & $\mathrm{~L}$ & 6 & 3 & 3 & 3 & 2 & 2 & 2 & Inflammation and mast cells \\
\hline 4 & 21 & L & 6 & 4 & 2 & 3 & 2 & $\overline{1}$ & 1 & Fibroblast activity, occasional mast cells \\
\hline 5 & 19 & L & 48 & 3 & 2 & 3 & 2 & 1 & 1 & Skeletal muscle fibre regeneration, no inflammation \\
\hline 6 & 23 & L & 48 & 1 & 2 & 2 & 2 & 1 & 2 & Lymphocytes and capillaries \\
\hline 7 & 18 & $\mathrm{R}$ & 6 & 2 & 2 & 1 & 2 & 1 & 1 & Lymphocytes \\
\hline 8 & 17 & $\mathrm{R}$ & 9 & 2 & 2 & 2 & 2 & 1 & 2 & Lymphocytes and capillaries \\
\hline 9 & 19 & $\mathrm{R}$ & 5 & 2 & 3 & 3 & 2 & 1 & $\overline{1}$ & Lymphocytes, capillaries and venules \\
\hline 10 & 26 & $\mathrm{R}$ & 24 & 2 & 2 & 2 & 2 & 1 & 1 & Capillaries, arterioles and venules \\
\hline 11 & 21 & $\mathrm{R}$ & 24 & 1 & 2 & 2 & 1 & 1 & 1 & Lymphocytes and capillaries \\
\hline 12 & 18 & L & 18 & 2 & 2 & 3 & 3 & 1 & 1 & Capillaries, thicker walled vessels \\
\hline 13 & 21 & $\mathrm{R}$ & 6 & 2 & 2 & 2 & 1 & 1 & 1 & Lymphocytes and capillaries \\
\hline 14 & 17 & $\mathrm{R}$ & 4 & 2 & 2 & 3 & 1 & 1 & 2 & Lymphocytes and capillaries \\
\hline 15 & 32 & $\mathrm{R}$ & 36 & 2 & 4 & 3 & 3 & 3 & 2 & 'Vasculitis', lymphocytes, disorganised collagen \\
\hline 16 & 19 & $\mathrm{R}$ & 60 & 2 & 3 & 2 & 2 & 2 & 1 & Lymphocytes and capillaries \\
\hline 17 & 17 & $\mathrm{R}$ & 30 & 2 & 3 & 2 & 3 & 2 & 1 & Mast cells (collagen and perivascular), vasculitis \\
\hline 18 & 19 & $\mathrm{~L}$ & 7 & $\overline{1}$ & 2 & $\overline{1}$ & 1 & $\overline{1}$ & 1 & Lymphocytes, normal skeletal muscle fibres \\
\hline 19 & 17 & L & 6 & 2 & 2 & 2 & 2 & 1 & 1 & Lymphocytes and capillaries \\
\hline Sum & 388 & & 379 & & & & & & & \\
\hline Mean & 20.42 & & 19.95 & & & & & & & \\
\hline \multicolumn{11}{|c|}{ Controls } \\
\hline 1 & 25 & $\mathrm{R}$ & - & 1 & 2 & 2 & 3 & 1 & 2 & Capillaries and disrupted collagen \\
\hline 2 & 29 & $\mathrm{R}$ & - & 2 & 2 & 2 & 3 & 1 & 1 & Collagen changes, lymphocytes and capillaries \\
\hline 3 & 34 & $\mathrm{R}$ & - & 2 & 2 & 2 & 2 & 1 & 2 & Lymphocytes and capillaries \\
\hline 4 & 18 & $\mathrm{~L}$ & - & 2 & 3 & 3 & 2 & 1 & 1 & Lymphocytes and capillaries \\
\hline 5 & 29 & L & - & 2 & 2 & 3 & 3 & 1 & 2 & Capillaries and distorted collagen arrangement \\
\hline 6 & 32 & $\mathrm{R}$ & - & 2 & 2 & 2 & 3 & 1 & 2 & Mast cells, occasional lymphocytes \\
\hline 7 & 19 & $\mathrm{R}$ & - & 2 & $\overline{1}$ & $\overline{1}$ & 3 & 1 & 1 & Remodelled collagen \\
\hline 8 & 26 & L & - & 1 & 1 & 1 & 2 & 1 & 2 & Normal skeletal muscle fibres \\
\hline 9 & 30 & $\mathrm{R}$ & - & 3 & 2 & 2 & 4 & 1 & 2 & Fibrocytes, lymphocytes \\
\hline 10 & 24 & $\mathrm{R}$ & - & 1 & 2 & 1 & 2 & 1 & 2 & Lymphocytes, remodelled collagen \\
\hline 11 & 23 & $\mathrm{R}$ & - & 1 & 2 & 1 & 2 & 1 & 1 & Mast cells \\
\hline Sum & 289 & & & & & & & & & \\
\hline Mean & 26.27 & & & & & & & & & \\
\hline
\end{tabular}

Histological grading scores: 1, normal; 2, mild abnormality; 3, moderate abnormality; 4, severe abnormality.

Fibro, Fibrocyte activity; CIC, chronic inflammatory cells; Vasc, vascularity; Coll, collagen regularity; Mono, mononuclear cells; GC, ground substance. 


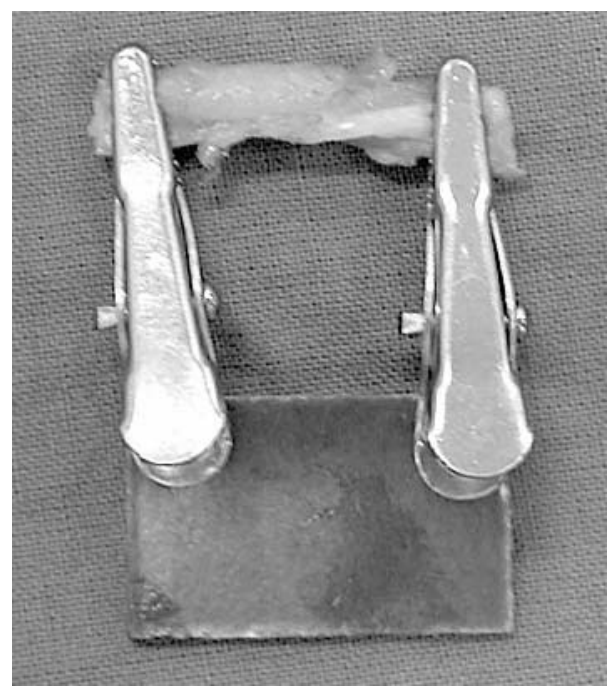

Figure 1 Alligator clip tissue fixation device.

changes just described was not regarded as an exclusion criterion (refer to discussion section). No subject in this study had thallium or MIBI based perfusion scanning.

\section{Tissue sampling}

The surgery was performed by the same surgeon in all cases. In some cases, anterior compartment surgery was also required depending on the clinical presentation. In these cases, tissue samples were only taken from the deep posterior compartment. The surgery was bilateral in 17 cases and unilateral in two cases. In cases of bilateral surgery, tissue samples were collected from one side only, on a random basis.

\section{Sampling and fixation technique}

At surgery, an 8-10 cm incision was made at the junction of the lower third and upper two thirds of the medial tibial border. The periosteum at that site was excised from the tibia and the fascial-periosteal interface was dissected away en bloc. The tissue was clamped using an alligator clip device to prevent retraction (fig 1) and immediately fixed in $10 \%$ buffered formalin. Samples that had splinters of cortical bone from the tibial cortex were subjected to acid decalcification, and all samples were embedded in paraffin. The samples were then sectioned $(3-5 \mu \mathrm{m})$ and stained (haematoxylin and eosin and Masson's trichrome methods).

\section{Control tissue}

Eleven control tissue samples were obtained from autopsy cases at the Victorian Institute of Forensic Medicine (VIFM) between March 2000 and June 2000 (table 1). There were 10 men and one woman (age range 18-34 years; mean 26.3) These tissue samples were obtained within 72 hours of their arrival at the VIFM. The exercise history was not known. The primary investigator, using the same technique as the surgeon in obtaining the subject tissue, obtained these samples and immediately fixed them in 10\% buffered formalin. They were then prepared, sectioned, and stained in the same manner as the subject tissue.

\section{Histological assessment}

A system based on that used by Bhatt et $a^{34}$ was then used to grade six histological variables identifying normal and abnormal appearance. Each variable was scored as follows: 1, normal; 2, mild abnormality; 3, moderate abnormality; 4, severe abnormality. The same pathologist examined all slides and was blinded as to the slide being a subject or control. On a separate occasion 16 slides were re-examined (eight subjects and eight controls) to give an intraobserver reliability score.

On the haematoxylin and eosin stained sections, variables examined were:

(1) Fibrocyte activity: number and activity of fibrocytes. This is used to indicate the presence of tissue remodelling.

(2) Chronic inflammatory cells: number and activity. Comment was also made on the predominant type of cell if present-that is, plasma, macrophage, or lymphocyte. These indicate the presence and extent of a chronic inflammatory process.

(3) Vascularity: score was based on wall thickness, structure, and number of vessels observed. The presence of neovascularisation again may indicate a remodelling process.

On the Masson's trichrome stained sections, variables examined were:

(1) Collagen fibre regularity: based on collagen density, fibre arrangement, orientation, and spacing.

(2) Mononuclear cells: number and activity. These indicate the presence and extent of a chronic inflammatory process.

(3) Ground substance: based on content in the vicinity of the collagen fibres. The latter variable is to be used as an (inverse) correlation with collagen density and chronic inflammatory cellular presence.

Each slide was examined at a magnification of 10, with 20 or 40 magnification used if cellular confirmation was needed. Comment was made with regard to the chronic inflammatory cellular type, vascular features, collagen arrangement, and any other point of interest such as the presence of other cell types.

\section{Statistical methods}

Results were decoded and tabled. Mann-Whitney U tests were performed, comparing ranked subject scores with ranked control scores for each separate variable, and significance values were obtained. Spearman correlation coefficients ( $r$ value) were performed between each variable, and also the subjects' symptom duration was correlated with each variable. An $r$ value of 1.0 indicates perfect correlation. Spearman's $r$ values were used to assess intraobserver reliability. Mononuclear scores were found to be of good reliability $(r=0.81)$, chronic inflammatory cells and vascular scores were of moderate reliability $(r=0.59$ for both), but fibrocyte activity $(r=0.29)$, collagen $(r=0.28)$, and ground substance $(r=0.29)$ had poor observer reliability. $\kappa$ coefficients, which give a better indication of reliability than Spearman's $r$ values, were calculated. However, because of the lack of numbers across all the score grades, values for some variables could not be calculated. To overcome this, grades 1 and 2 were combined, as were grades 3 and 4 . This gave $\kappa$ values of 0.18 for fibrocyte activity (poor), 0.77 for chronic inflammatory cells (good), 0.48 for vascularity (moderate), and 0.26 for collagen fibre quality (poor). Values for mononuclear and ground substance could not be calculated.

\section{Ethical considerations}

This study has ethics committee approval by the Melbourne Research and Innovation Office, Melbourne University (project No 980054) and the Research and Related Projects Committee, Victorian Institute of Forensic Medicine. Consent 

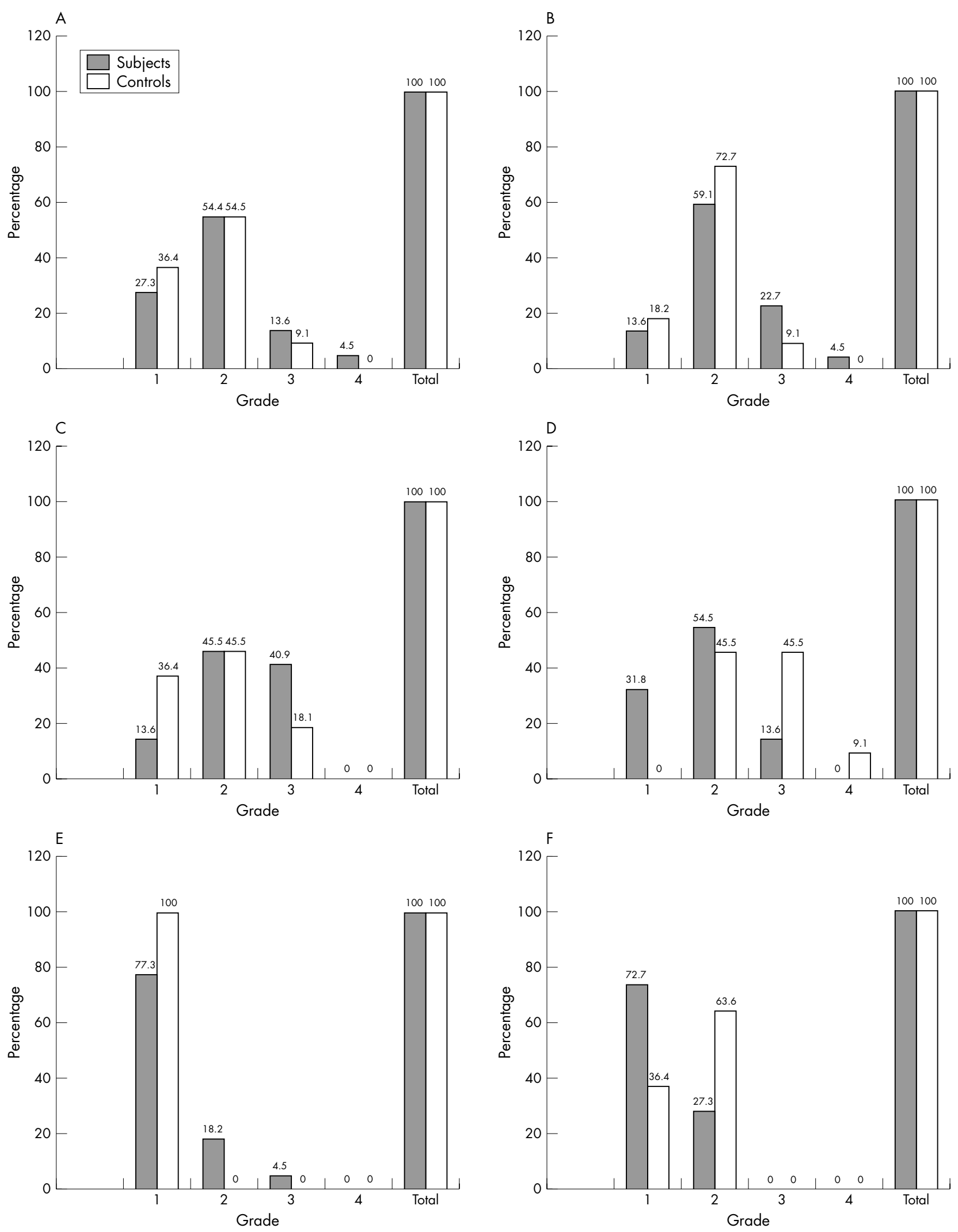

Figure 2 Percentage of subjects and controls with each histological variable plotted against grade of abnormality (1, normal; 2, mild abnormality; 3 , moderate abnormality; 4 , severe abnormality). A, Fibrocyte activity; B, chronic inflammatory cells; $C$, vascularity; $D$, collagen regularity; $E$, mononuclear cells; F, ground substance. 
Table 2 Comparison of ranked subject scores with ranked control scores for each variable

\begin{tabular}{lllllll}
\hline & Fibro & CIC & Vasc & Coll & Mono & GS \\
\hline Mann-Whitney U score & 85 & 72.5 & 66.5 & 50 & 82.5 & 71 \\
Z score & -0.96 & -1.651 & -1.769 & -2.581 & -1.604 & -1.679 \\
Significance (two tailed) & 0.337 & 0.099 & 0.077 & 0.01 & 0.109 & 0.093 \\
\hline
\end{tabular}

Fibro, Fibrocyte activity; ClC, chronic inflammatory cells; Vasc, vascularity; Coll, collagen regularity; Mono, mononuclear cells; GC, ground substance.

was obtained from the subjects themselves or a parent of the 17 year old subjects. The consenting procedure for the controls was performed by a member of staff at the Institute of Forensic Medicine and was obtained from the next of kin.

\section{RESULTS}

Table 1 shows the scores given for each individual histological variable and relevant comment. Table 2 shows the Mann-Whitney U test results for each variable and its significance. The results for each variable were plotted according to grade of abnormality and the corresponding percentage of subjects and controls with each score (fig 2).

Collagen scores produced a significant result (fig 2D). Control tissue showed significantly higher degrees of irregularity ( $\mathrm{p}=0.01$; Mann-Whitney $\mathrm{U}$ test). Comments predominantly referred to a disrupted and distorted arrangement (fig 3) and that a disruptive process had been present but was no longer active. Conversely subjects' tissue collagen appeared largely orientated and uniform, although in those subjects receiving a score of 3, two were those also scoring highly in vascular and chronic inflammatory cellular variables. A significant finding did occur when subjects were divided into two groups based on symptom duration. In 10, symptom duration was $\leqslant 12$ months, and in nine it was $>12$ months. Collagen irregularity was significantly greater in subjects with longer symptom duration $(\mathrm{p}=0.043$; Mann-Whitney U test). There were no significant differences when other variables were compared in this way.

Fibrocyte activity was largely scored as normal or mildly abnormal (fig 2A). One subject showed highly active fibroblasts (fig 4). With regard to chronic inflammatory cells, the vast majority were lymphocytes, both in subjects and controls (fig 2B). Mast cells were found in three subjects; in one case these were widespread throughout the collagen and perivascular tissues (fig 5), and in another abundant mast cells were seen. Mast cells were noted in two control cases.

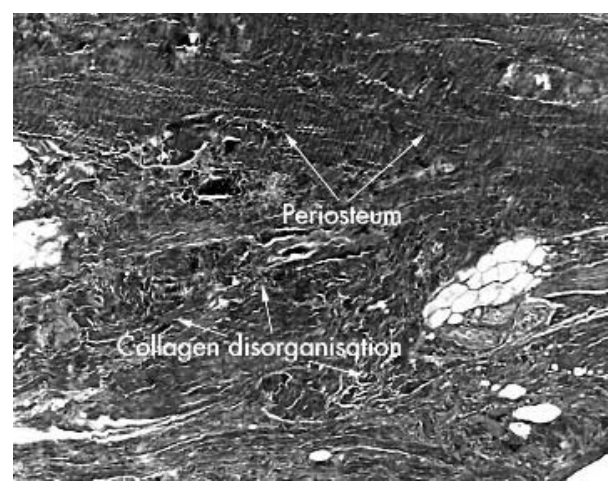

Figure 3 Periosteum is seen at top of the slide, and disorganised collagen is present throughout the lower part. $10 \times$ magnification, Masson's trichrome stain.

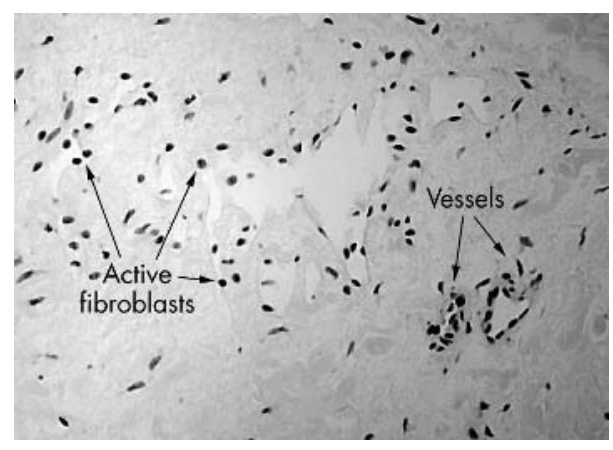

Figure 4 Active fibroblasts displaying rounded nuclei are shown. $20 \times$ magnification, haematoxylin and eosin stain.

In the assessment of vascular changes (fig $2 \mathrm{C}$ ), there were no scores of 4 for either group, and, although there was a tendency for the subjects to score higher degrees of abnormality, again no significant difference existed between subject and control groups $(\mathrm{p}=0.077$; Mann-Whitney $\mathrm{U}$ test). Of interest, there were several individual subjects who displayed "vasculitis-like" changes, with wall thickening, tortuosity, and chronic inflammatory cellular infiltrates. An example is shown in fig 6. No such vascular changes were seen in any control tissue.

Mononuclear cells (fig 2E) and ground substance (fig 2F) received predominantly normal/mild abnormality scores in both groups.

There was no significant difference between subject and control scores for the fibrocyte, chronic inflammatory cell, monocyte, or ground substance variables (table 2; MannWhitney U tests).

\section{Correlations}

Spearman rank correlations were performed. Table 3 shows the coefficient scores and significance values. Subject and control scores were combined for this correlation, except for

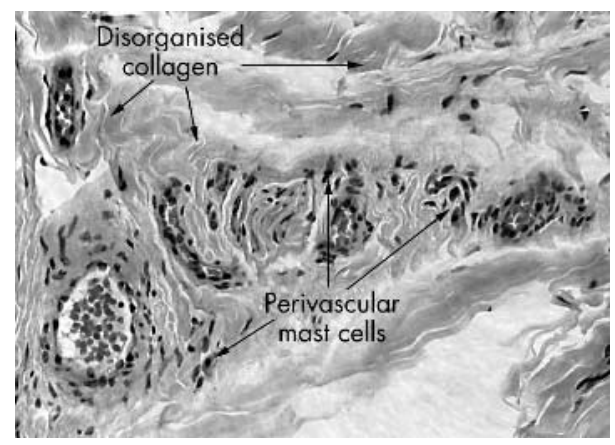

Figure 5 Perivascular mast cells are shown in a case also displaying disorganised collagen. $20 \times$ magnification, haematoxylin and eosin stain. 


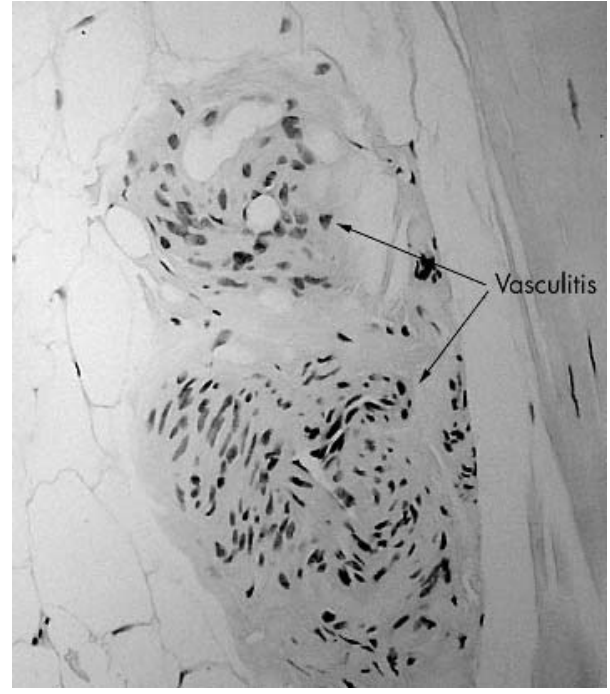

Figure 6 Significant vascular change, with thickened wall, tortuosity, and lymphocytic infiltration. $20 \times$ magnification, haematoxylin and eosin stain.

symptom duration scores, which were only correlated against subject scores.

Good to moderate correlation is seen between fibrocyte and vascular variables, and also between chronic inflammatory cells and monocyte variables.

Correlation between symptom duration and the other subject variables generally were not strong, as seen by the figures in the symptom column. It was expected that histopathology within subjects might depend on the duration of symptoms. This, however, did not seem to be the case, except for collagen, as stated above, which showed greater irregularity in subjects with longer duration of symptoms.

\section{DISCUSSION}

Based on the hypothesis that repetitive microtrauma at the fascial-periosteal interface results in local histopathological

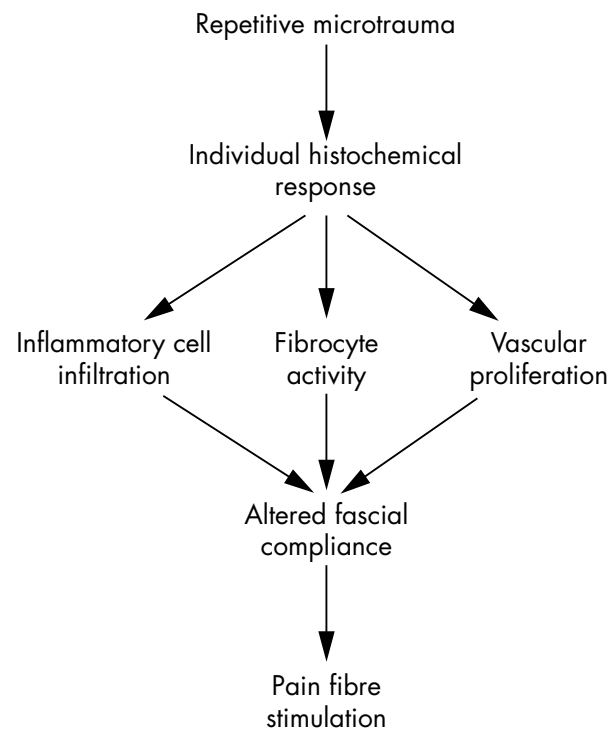

Figure 7 Flow chart showing the proposed cascade of physiological events leading to deep posterior compartment syndrome.

alterations, this study attempted to examine the histological features of the fascia and its periosteal interface in subjects with CECS of the deep posterior compartment. A grading scale and descriptive analyses of histological features were used. The results show that collagen in subjects with the condition appeared significantly less irregular-that is, scored lower grades of abnormality based on fibre density, arrangement, and orientation-and, although histological appearance varied, other variables showed no significant differences.

\section{Inflammatory findings}

Although one study reported no signs of inflammation in biopsy specimens from patients with $\mathrm{CECS}^{3}$ our results concur with previous work in that a proportion of fascial

Table 3 Spearman's rank correlation coefficient scores and significance value for each histological variable

\begin{tabular}{|c|c|c|c|c|c|c|c|c|}
\hline & & Fibr & $\mathrm{CIC}$ & Vasc & Coll & Mono & GS & Symp \\
\hline \multirow[t]{2}{*}{ Fibr } & Correlation coefficient & 1 & 0.145 & 0.574 & 0.306 & 0.235 & -0.044 & -0.192 \\
\hline & $\mathrm{N}$ & 30 & 30 & 30 & 30 & 30 & 30 & 19 \\
\hline \multirow[t]{2}{*}{$\mathrm{ClC}$} & $\begin{array}{l}\text { Correlation coefficient } \\
\text { Significance ( } 2 \text { tailed) }\end{array}$ & & 1 & $\begin{array}{l}0.368 \\
0.045\end{array}$ & $\begin{array}{l}-0.024 \\
0.901\end{array}$ & $\begin{array}{l}0.649 \\
<0.001\end{array}$ & $\begin{array}{l}-0.182 \\
0.337\end{array}$ & $\begin{array}{l}0.12 \\
0.624\end{array}$ \\
\hline & $\mathrm{N}$ & & 30 & 30 & 30 & 30 & 30 & 19 \\
\hline \multirow[t]{3}{*}{ Vasc } & Correlation coefficient & & & 1 & 0.091 & 0.206 & 0.118 & -0.083 \\
\hline & Significance ( 2 tailed) & & & & 0.634 & 0.276 & 0.536 & 0.736 \\
\hline & $\mathrm{N}$ & & & 30 & 30 & 30 & 30 & 19 \\
\hline \multirow[t]{3}{*}{ Coll } & Correlation coefficient & & & & 1 & 0.209 & 0.239 & 0.376 \\
\hline & Significance ( 2 tailed) & & & & & 0.268 & 0.202 & 0.112 \\
\hline & $\mathrm{N}$ & & & & 30 & 30 & 30 & 19 \\
\hline \multirow[t]{3}{*}{ Mono } & Correlation coefficient & & & & & 1 & 0.066 & 0.367 \\
\hline & Significance ( 2 tailed) & & & & & & 0.73 & 0.122 \\
\hline & $\mathrm{N}$ & & & & & 30 & 30 & 19 \\
\hline \multirow[t]{2}{*}{ GS } & $\begin{array}{l}\text { Correlation coefficient } \\
\text { Significance ( } 2 \text { tailed) }\end{array}$ & & & & & & 1 & $\begin{array}{l}0.031 \\
0.899\end{array}$ \\
\hline & $\mathrm{N}$ & & & & & & 30 & 19 \\
\hline \multirow[t]{2}{*}{ Symp } & $\begin{array}{l}\text { Correlation coefficient } \\
\text { Sianificance }(2 \text { tailed }\end{array}$ & & & & & & & 1 \\
\hline & $\mathrm{N}$ & & & & & & & 19 \\
\hline
\end{tabular}

In the Symp column, symptom duration is correlated against each variable. The number $(\mathrm{N})$ in this column is 19 , as it only correlates with subjects and does not include controls.

Fibr, Fibrocyte changes; CIC, chronic inflammatory cells; Vasc, vascular changes; Coll, collagen arrangement; Mono, monocytes; GS, ground substance; Symp, symptom duration of subjects. 
samples show signs of histological alteration. Turnipseed et al $^{29}$ examined fascial samples in 209 patients surgically treated for CECS: $40 \%$ showed increased thickness without inflammation, $14 \%$ inflammatory changes without scarring, and $46 \%$ were normal. Detmer et $a l^{2}$ found fascial hypertrophy in $69 \%$ of specimens sampled; however, the lack of normal data made interpretation difficult. A further study by Detmer ${ }^{17}$ showed adipose tissue between the bone and periosteum in patients with MTSS, but no such changes were seen in those with CECS. This is consistent with this study in that no adipose tissue was seen adjacent to the periosteum.

Mubarak et $a^{16}$ found histological signs of periostitis and vasculitis in fascial samples from two cases of MTSS and regarded this condition as a separate entity from CECS. Johnell et $a^{35}$ examined bone and soft tissue samples (consisting of fascia and periosteum) in patients surgically treated for medial tibial pain, the diagnosis of which was broad and did not distinguish between CECS and MTSS. In 13 of the 33 soft tissue biopsy specimens, there were inflammatory changes in the fascia. These changes consisted of focal aggregates of lymphocytes, with occasional histiocytes and mast cells surrounding and infiltrating the walls of small arteries. Cells often split the arterial wall, giving the appearance of arteritis. In only one instance was the periosteum affected. In several ways these findings are similar to our study, in which several subjects had changes including perivascular lymphocytic infiltrates, endothelial cell abnormalities, and vessel tortuosity, these being consistent with a "vasculitis". The presence of mast cells is also noted in three cases, although their significance is uncertain. In the study of Johnell et al, ${ }^{35}$ bone samples were also taken, making periosteal differentiation possible. In our study, we kept the surgical procedure identical with that normally undertaken, so no significant tibial bone was excised. This did result in some loss of periosteal differentiation, and no comment can be made about specific periosteal changes. With these studies showing a percentage of samples having chronic inflammatory changes, repetitive trauma and inflammation may account for fascial abnormalities in only a subgroup of patients, whereas histochemical properties may alter fascial compliance in the absence of histopathology, but when the condition still exists. ${ }^{29}$

More recently, Bhatt $e t$ al $^{34}$ found "abnormal" periosteum in 21 out of 32 cases of MTSS, measured in terms of fibrosis, vascularity, mucin production, and iron deposition. The grades (1, 2, 3 or 4) for each histological variable were added, and a combined score of six was considered abnormal. As there were no controls for normal variables, this arbitrary value was used as a cut off. Our study allowed statistical analysis directly against control tissue, and showed that, for similar histological variables, no significant differences exist and thus we are unable to support Bhatt's conclusion. This was especially so for fibrocyte changes, which showed a significance value of 0.337 (table 2). Vascular changes approached significance at 0.077 , and chronic inflammatory cellular changes had a significance value of 0.099 (MannWhitney $\mathrm{U}$ test). It could be that medial tibial periostalgia is a syndrome characterised by greater histopathological abnormalities, but the possibility that the results of Bhatt et al might have differed if comparative control tissue was present cannot be disregarded.

\section{Vascular findings}

Turnipseed $e t$ al $^{26}$ evaluated anterior tibial arteriovenous flow patterns and whether mechanical and biochemical properties of fascia were responsible for compartment pressure abnormalities. They describe the loss of spontaneous and phasic tibial vein flow in cases of CECS of the anterior compartment. This was regarded as not being due to obstructive or anatomical abnormalities within the venous system per se, but to abnormal mechanical and histochemical characteristics of the fascia and myofascial scarring. The results of our study support this concept, in that there is no significant difference in microscopic vascular changes between subjects and controls. Although individual cases show perivascular inflammatory changes, it is unclear whether this represents a primary vascular response or a more diffuse inflammatory one. Our study suggests that the different histochemical variables of individuals may give rise to different patterns of histological change. Two other subjects, for example, show predominantly fibroblastic activity with minimal inflammatory changes.

\section{Collagen findings}

Given that past studies have shown the fascia in this condition to be thickened in some cases, ${ }^{26}$ it was expected that the collagen of subjects would score more highly-that is, appear more irregular-than that of controls. This was not the case. It has been reported by Elliott, ${ }^{37}$ and Rodbard ${ }^{38}$ and cited by Detmer et al ${ }^{2}$ that tensile forces stimulate fibroblasts to remodel collagen, the direction of which determines the orientation, increasing the fascia's density and strength. Turnipseed et al ${ }^{26}$ showed that collagen cross linkage was reduced in CECS fascia, suggesting that neocollagen formation may be occurring particularly in areas of increased strain load (myofascial scarring) and that CECS fascia was thicker and stiffer than controls. Our study showed that subjects with longer symptom duration displayed greater degrees of collagen irregularity. It was beyond the scope of this study to measure fascial thickness or tensile strength; however, our results may reflect a similar process of fascial reorganisation in response to load. This was borne out by the scoring system used, rewarding low scores for more orientated fascia seen in subjects and higher scores for the less orientated fascia seen in controls. With regard to the terminology used, collagen appeared more "irregular", although it is plausible that it is in fact the true normal appearance of fascia at this site; it has just not been identified in such a way in past studies. These observed changes raise the question of a possible association between collagen regularity (as seen in subjects) and reduced fascial compliance. Further studies are required to measure mechanical length and tension properties of fascia in cases of CECS, coupled with histological variables. There is a paucity of histological studies in this field using any controls for comparisons, and therefore the features of control/normal fascia are really not known. A further point to raise is that in the ideal setting, control tissue for this study would have been from athletes without CECS, but exercising at loads similar to the subjects with it. Clearly to take tissue from such a population would raise significant ethical problems. It is noted that control tissue was taken by the principal author and not the surgeon and that the exercise history of the control cases was not known. We feel, however, that these would not totally account for the histological differences.

Another facet of the study of Bhatt et $a l^{34}$ was the measurement of periosteal thickness, for which a value greater than $1 \mathrm{~mm}$ was considered abnormal. Dividing the cases into two groups based on normal and abnormal periosteal thickness, Fisher's exact test was performed against those with normal and abnormal bone scans. In the study of Bhatt et al, abnormal scans were seen almost exclusively in cases of low periosteal thickness and conversely increased thickness was mostly seen with normal scans. The interpretation suggested that a thick periosteum indicated a late disease phase where reparative changes are well 
advanced and an abnormal scan less likely. This could be a further example of collagen reorganisation.

\section{Correlation between histological variables}

With regard to the remodelling theory alluded to, it could be postulated that particular histological changes occur as the duration of symptoms progress. For this reason each histological variable was correlated against symptom duration (table 3). Collagen appeared more irregular in subjects with a symptom duration greater than 12 months, but otherwise no significant correlations were observed. Fibrocyte activity was high in one case in which symptoms had been present for six months, a relatively short time frame for chronic compartment syndrome. This may indicate a more active, subacute process. However, correlation between symptom duration and fibrocyte activity overall was not significant $(r=-0.192)$. Two subjects showed vessel changes consistent with vasculitis. Symptom duration was 36 and 30 months. Although there was no correlation between vascular changes and symptom duration $(r=$ 0.083), this finding lends support to the concept that individual biochemical and cellular responses lead to various patterns of histological change. For example, regenerating skeletal muscle fibres were displayed in one subject, but there was no significant inflammatory change present. It may be an individual's response to similar patterns and duration of loading that leads to the variations observed. However, sampling of isolated areas may not indicate more diffuse changes, and, in common with many histological studies, no sequential tissue sampling was performed. It is also difficult to interpret the significance values of Spearman correlation coefficients, as they are so dependent on sample size and measurement parameters. Therefore the significance values for correlation coefficients have not been quoted.

\section{Histological scoring system and intraobserver reliability}

Both our study and that of Bhatt et al are limited in that each used a subjective scoring system. In our study, correlation between the chronic inflammatory cells and monocyte variables was strong. This would be expected as they are similar variables, one viewed on haematoxylin and eosin stained sections, the other on Masson's trichrome. The subjectiveness, nevertheless, has been borne out by the intraobserver reliability scores being poor for some of the variables. No observer reliability scores were quoted for the study of Bhatt et al. More objective techniques, such as stereology, could be used to measure cellular numbers, but variables such as collagen regularity and cellular activity rely on the reporter's histological expertise. A good example of the difficulties faced is shown in the study by Rosai, ${ }^{36}$ who obtained histological assessment of 17 proliferative breast lesions by five different experts in the field. There were no cases in which all agreed on the diagnosis, in only $18 \%$ of cases four out of the five experts agreed, and in 33\% their diagnoses spanned the gamut of hyperplasia variants. This reflects the significant difficulties associated with measurement of histological variables. The reliability scores for this study admittedly reduce the impact of the statistical data obtained. Although descriptive analyses of histological tissue can give valuable information on conditions such as CECS, the conclusions drawn, especially with regard to collagen changes, may be a result of chance because of its low reliability score.

\section{Bone scintigraphy}

Bone scintigraphy is not regarded as an appropriate investigation for the positive diagnosis of CECS and is predominantly used to exclude stress fractures. The concept of a continuum of bone strain existing both clinically and scintigraphically is widely accepted, and in many athletes numerous areas of bone stress are found, which indicate bone remodelling rather than risk of development of stress fracture. ${ }^{39}$ Recruitment for this study occurred at the time of surgical consultation or after, and six of the 19 subjects recruited had not had bone scintigraphy. Of the 13 who had, nine were reported as having shin splints, stress reaction, or periostitis in a patchy or linear distribution. It was decided that inclusion in the study depended on failed conservative management with positive compartment pressure studies and therefore it was deemed unnecessary for subjects to have scintigraphy, as long as they fitted these criteria. This decision is supported by Bhatt et al, ${ }^{34}$ who showed a lack of correlation between abnormal scintigraphy and histological bone abnormalities. The latter study showed that subjects with thickened periosteum had mostly normal scintigraphy, and those with thin periosteum had mostly abnormal scintigraphy. Furthermore, if athletes were exercising enough to develop CECS, it would be likely that many, if not most, would show some kind of stress changes on bone scintigraphy. For these reasons, a normal bone scan was not regarded as essential for inclusion in the study, and a scan showing the features described above was not regarded as an exclusion criterion.

\section{Proposed response pathway}

Clearly the cascade of events leading to this condition has not been fully defined. More recent theories on the cause of pain in CECS include stimulation of fascial stretch receptors or intramuscular pressure receptors and the accumulation of metabolic byproducts. ${ }^{40}$ Apart from the early study of Qvarfordt et al, ${ }^{18}$ which found increased lactate in anterior compartment muscle biopsy samples, these theories have not been tested.

After initial mechanical stressors, the response pathway may diverge, depending on individual histochemical responses. Inflammatory cell infiltration, vascular proliferation, or fibrocytic activity then occurs at various times and to varying degrees (fig 7). The pathways may then converge, the end result being altered fascial compliance and pain fibre stimulation with further exercise. This hypothetical cascade of events may explain the variability of histological changes observed in the different samples obtained.

\section{CONCLUSION}

This study has attempted to outline the histological changes of the fascial-periosteal interface in patients with CECS and make comparisons with control tissue. Individual cases show various degrees of fibrocytic activity, chronic inflammatory cell presence, and vascular proliferation, but significant differences between subjects and controls did not exist for these variables. It may be that isolated samples represent different stages of this evolving condition. Collagen appeared significantly less irregular in the subject group, and it is proposed that this change is due to a remodelling process. Limitations to the interpretation of results include low intraobserver reliability scores for some of the variables, thus reducing the significance of some of the statistical data, and lack of access to a control group consisting of exercising athletes without the condition. The objective of this study in describing the histological features of patients with this condition has been achieved, but without prospective studies and sequential sampling the cascade of histopathological events must remain speculative. 


\section{What is already known on this topic}

CECS is a common problem encountered in sports medicine. Past research has shown the presence of chronic inflammatory changes, fibrocytic activity, vascular changes, and alterations in thickness and tensile strength of compartment fascia. Slowing of venous oufflow is thought to ensue and contribute to production of clinical symptoms.

\section{What this study adds}

This study confirms the presence of histological changes at the fascial-periosteal interface in subjects with CECS, but these are observed in variable amounts. Collagen appears less irregular in subjects, when compared with control fascia. It is proposed that this is due to a remodelling process. Prospective studies with sequential sampling of fascia are required.

\section{ACKNOWLEDGEMENTS}

The principal author is grateful for the guidance of Associate Professor Kim Bennell, who provided invaluable statistical advice. Thanks also to Helen Makin and the histology staff of the Department of Anatomy and Cell Biology and Dr Virginia Grossman, Department of Pathology, University of Melbourne. Their time, effort, and advice with regard to the preparation of the histology slides is appreciated.

\section{Authors' affiliations}

T D A Barbour, P D Brukner, Centre for Sports Medicine Research and Education, University of Melbourne, Melbourne, Australia

C A Briggs, Department of Anatomy and Cell Biology, University of Melbourne

S N Bell, C J Bradshaw, Olympic Park Sports Medicine Centre, Melbourne, Australia

D J Venter, Department of Pathology, University of Melbourne

No benefits in any form have been received or will be received from a commercial party related directly or indirectly to the subject of this article. No funds were received in support of this study.

\section{REFERENCES}

Michael RH, Holders LE. The soleus syndrome: a cause of medial tibial stress (shin splints). Am J Sports Med 1985;13:87-94.

2 Detmer D, Sharpe K, Sufit R, et al. Chronic compartment syndrome: diagnosis, management and outcomes. Am J Sports Med 1985;13:162-70.

3 Allen MJ, Barnes MR. Exercise pain in the lower leg. Chronic compartment syndrome and medial tibial syndrome. J Bone Joint Surg 1986;68:818-23.

4 Wiley JP, Short WB, Wiseman DA, et al. Ultrasound catheter placement for deep posterior compartment pressure measurements in chronic compartment syndrome. Am J Sports Med 1990;18:74-9.

5 Varelas FL, Wessel J, Clement DB, et al. Muscle function in chronic compartment syndrome of the leg. J Orthop Sports Phys Ther 1993;18:586-9. 6 Hayes AA, Bower GD, Pitstock, KL. Chronic (exertional) compartment syndrome of the legs diagnosed with thallous chloride scintigraphy. J Nud Med 1995;36:1618-24.

7 Wiley JP, Clement DB, Doyle DL, et al. A primary care perspective of chronic compartment syndrome of the leg. Phys Sportsmed 1987;15:110-20.

8 Pedowitz RA, Hargens AR, Mubarak SJ, et al. Modified criteria for the objective diagnosis of chronic compartment syndrome of the leg. Am J Sports Med 1990;18:35-40.
9 Balduini FC, Shenton DW, O'Connor KH, et al. Chronic exertional compartment syndrome: correlation of compartment pressure and muscle ischaemia utilising ${ }^{31}$ P-NMR spectroscopy. Clin Sports Med 1993; 12:151-65.

10 Clanton TO, Solcher BW. Chronic leg pain in the athlete. Clin Sports Med 1994:4:743-59.

11 Styf J. Diagnosis of exercise-induced pain in the anterior aspect of the lower leg. Am J Sports Med 1988;16:165-9.

12 Baquie P, Brukner P. Injuries presenting to an Australian Sports Medicine Centre: a 12-month study. Clin J Sport Med 1997;7:28-31.

13 Barnes M. Diagnosis and management of chronic compartment syndromes: a review of the literature. Br J Sports Med 1997;31:21-7.

14 Martens MA, Moeyersoons JP. Acute and recurrent effort-related compartment syndrome in sports. Sports Med 1990;9:62-8.

15 Wallensten R. Results of fasciotomy in patients with medial tibial syndrome or chronic anterior-compartment syndrome. J Bone Joint Surg [Am] 1983:65:1252-5

16 Mubarak SJ, Gould RN, Fon Lee Y, et al. The medial tibial stress syndrome: a cause of shin splints. Am J Sports Med 1982;10:201-5.

17 Detmer DE. Chronic shin splints. Classification and management of medial tibial stress syndrome. Sports Med 1986;3:436-46.

18 Qvarfordt P, Christenson J, Eklof B, et al. Intramuscular pressure, muscle blood flow and skeletal muscle metabolism in chronic anterior tibial compartment syndrome. Clin Orthop 1983;179:284-90.

19 Styf J, Korner I, Suurkula M. Intramuscular pressure and muscle blood flow during exercise in chronic compartment syndrome. J Bone Joint Surg 1987;69:301-5.

20 Styf J. Chronic exercise induced pain in the anterior aspect of the lower leg. An overview of the diagnosis. Sports Med 1989:7:331-9.

21 Black KP, Taylor DE. Current concepts in the treatment of common compartment syndromes in athletes. Sports Med 1993;15:408-18.

22 Hutchinson MR, Lloyd-Ireland M. Common compartment syndromes in athletes: treatment and rehabilitation. Sports Med 1994;17:200-8.

23 Pedowitz RA, Gershuni GH. Pathophysiology and diagnosis of chronic compartment syndrome. Oper Tech Sports Med 1995;3:230-6.

24 Mohler LR, Styf JR, Pedowitz RA, et al. Intramuscular deoxygenation during exercise in patients who have chronic anterior compartment syndrome of the leg. J Bone Joint Surg 1997;79:844-9.

25 Amendola $A$, Rorebeck $C H$, Vellett $D$, et al. The use of magnetic resonance imaging in exertional compartment syndromes. Am J Sports Med 1990; 18:29-34.

26 Turnipseed WD, Hurschler C, Vanderby R. The effects of elevated compartment pressure on tibial arteriovenous flow and relationship of mechanical and biochemical characteristics of fascia to genesis of chronic anterior compartment syndrome. J Vasc Surg 1995;21: 810-16.

27 Trease L, Van Every B, Bennell K, et al. A prospective, blinded evaluation of exercise TL-201 SPECT in patients with suspected chronic exertional compartment syndrome of the leg. Eur J Nucl Med 2001;28:688-95.

28 Owens S, Edwards P, Miles K, et al. Chronic compartment syndrome affecting the lower limb: MIBI perfusion imaging as an alternative to pressure monitoring: two case reports. Br J Sports Med 1999;33:49-53.

29 Turnipseed W, Detmer D, Girdley F. Chronic compartment syndrome. an unusual cause for claudication. Ann Surg 1989;210:557-63.

30 Brukner P, Khan K, Bradshaw C. Shin pain. In: Brukner P, Khan K, eds. Clinical sports medicine, 2nd ed. Sydney: McGraw Hill, 2002:508-23.

31 Bates P. Shin splints: a literature review. Br J Sports Med 1985;19:132-7.

32 Abramowitz AJ, Schepsis AA. Chronic exertional compartment syndrome of the lower leg. Orthop Rev 1994;23:219-25.

33 Touliopolous S, Hershman EB. Lower leg pain. Diagnosis and treatment of compartment syndromes and other pain syndromes of the leg. Sports Med 1999;27:193-204.

34 Bhatt R, Lauder I, Finlay DB, et al. Correlation of bone scintigraphy and histological findings in medial tibial syndrome. Br J Sports Med 2000;34:49-53.

35 Johnell O, Rausing A, Wendeberg B, et al. Morphological bone changes in shin splints. Clin Orthop 1982;167:180-4

36 Rosai J. Borderline epithelial lesions of the breast. Am J Surg Path $1991 ; 15: 209-21$.

37 Elliott D. Structure and function of mammalian tendon. Biol Rev 1965;40:392-421.

38 Rodbard S. Negative feedback mechanisms in the architecture and function of the connective and cardiovascular tissues. Perspect Biol Med 1970;13:507-27.

39 Brukner P. Exercise-related lower leg pain: bone. Med Sci Sports Exerc 2000;32:S15-26.

40 Humphries D. Exertional compartment syndromes. Orthop Sports Med (serial online) 1999;3. 